\title{
LA PRELACIÓN DE LOS INSTRUMENTOS QUE COMPONEN UN PLAN REGULADOR
}

\author{
THE HIERARCHY OF THE INSTRUMENTS THAT \\ MAKE UP AN URBAN REGULATORY PLAN
}

INFORME EN DERECHO

\begin{tabular}{|c|c|}
\hline CÓMO CITAR ESTE ARTíCUlo (CHICAGO) & 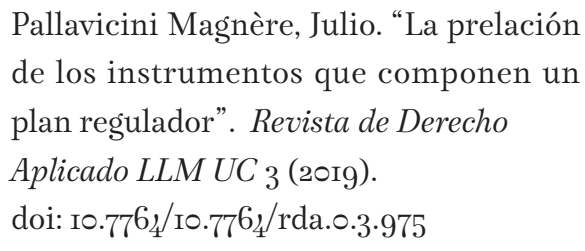 \\
\hline REVISTA DE DERECHO APLICADO LLM UC & $\begin{array}{l}\text { Número } 3 \\
\text { Julio } 2019 \\
\text { ISSN: } 245^{2-4344}\end{array}$ \\
\hline
\end{tabular}




\section{Resumen}

El presente trabajo analiza los planes reguladores metropolitanos, que están compuestos de tres elementos: la memoria explicativa, que contiene los objetivos, metas y programas del Plan Regulador Intercomunal, 2) la ordenanza, que contiene las disposiciones reglamentarias pertinentes, y 3 ) los planos, que expresan gráficamente las disposiciones sobre zonificación general, equipamiento, relaciones viales, áreas de desarrollo prioritario, límites de extensión urbana, densidades, entre otros. El autor plantea que existe una jerarquía entre estos instrumentos, en términos tales que en caso de discrepancia, prima el Plan Regulador, enseguida la ordenanza y, finalmente, los planos. Para sostener esta tesis, se basa en argumentos de texto contenidos en la la Ley General de Urbanismo y Construcciones, en la jurisprudencia de la Corte Suprema chilena y en la doctrina y la jurisprudencia internacional de referencia más destacada.

Palabras clave: urbanismo, área preservación ecológica, área urbana metropolitana, derecho urbanístico, Barrio Orcasitas

\section{Abstract}

This paper analyzes the metropolitan regulatory plans, which are composed of three elements: the explanatory memory, which contains the objectives, goals and programs of the Intercommunal Regulatory Plan, 2) the ordinance, which contains the relevant regulatory provisions, and 3) the plans, that graphically express the provisions on general zoning, equipment, road relationships, priority development areas, urban extension limits, densities, among others. The author states that there is a hierarchy between these instruments, in terms such that in case of discrepancy, the Regulatory Plan prevails, then the ordinance and, finally, the plans. To support this thesis, he bases on text arguments contained in the General Law of Urbanism and Constructions, in the jurisprudence of the Chilean Supreme Court and in the doctrine and international jurisprudence of most outstanding reference.

Keywords: town planning, ecological preservation area, metropolitan urban area, urbanistic right, Orcasitas neighborhood 


\section{Julio Pallavicini Magnère}

Universidad de Chile

Facultad de Derecho

Santiago, Chile

jpallavicini@derecho.uchile.cl

Universidad de Chile

Faculty of Law

Santiago, Chile

jpallavicini@derecho.uchile.cl
Julio Pallavicini Magnère es profesor asociado de la Facultad de Derecho de la Universidad de Chile. Abogado, licenciado en Ciencias Jurídicas y Sociales de la Universidad de Chile y Máster en derecho (LL.M.) de la Universidad de Cornell, Nueva York, es profesor de derecho administrativo, con numerosas publicaciones en forma de libros, capítulos y artículos de derecho. Es consejero del Departamento de Derecho Público de la la Facultad de Derecho de la Universidad de Chile, socio fundador de Gómez, Pallavicini \& García Abogados y a su vez es abogado integrante de la Corte Suprema, asignado preferentemente a la $3^{\text {a }}$ Sala.

Julio Pallavicini Magnère is an associate professor at the Faculty of Law of the Universidad de Chile, having obtained his law degree at the Universidad de Chile. He holds a Master of Laws (LL.M.) from Cornell University, New York and is a professor of administrative law, having published multiple books, book chapters and papers on his field of specialty. He is an advisor at the Department of Public Law of the Faculty of Law, Universidad de Chile, is the founder of Gómez, Pallavicini $\&$ García and is a Supreme Court Justice assigned to the Third Chamber. 


\section{Introducción}

En el año 1994, el Gobierno Regional Metropolitano de Santiago dictó la Resolución No 20 que aprobó el Plan Regulador Metropolitano de Santiago (en adelante, PRMS), cuyo objeto fue regular el desarrollo físico de las áreas urbanas y rurales de diversas comunas de la Región Metropolitana, que integran una unidad urbana.

Como todo documento de esta naturaleza, el PRMS se compone por tres instrumentos: 1) la Memoria Explicativa, el instrumento de planificación territorial que contiene los objetivos, metas y programas del Plan Regulador Intercomunal ${ }^{1}$; 2) una ordenanza, que contiene las disposiciones reglamentarias pertinentes; y 3) los planos, que expresan gráficamente las disposiciones sobre zonificación general, equipamiento, relaciones viales, áreas de desarrollo prioritario, límites de extensión urbana y densidades, entre otros².

En un plan bien diseñado, debería existir coincidencia en el contenido sustantivo de cada uno de estos instrumentos. Sin embargo, en ocasiones contienen diferencias significativas, y en tales casos será necesario interpretarlos armónicamente. Dado que las diferencias entre los instrumentos pueden ser radicales, la mayoría de las veces habrá que optar por una de ellas, desplazando a la otra: o es válido lo expresado en la Memoria Explicativa o lo es lo señalado en los planos.

Por ejemplo, la Memoria Explicativa del PRMS fijó los límites para la "preservación ecológica" de las comunas de La Reina, Peñalolén, La Florida y Puente Alto sobre la cota 900 metros sobre el nivel del mar, en adelante m.s.n.m., y para las comunas de Las Condes, Lo Barnechea y Vitacura sobre la cota 1.000 m.s.n.m.

En su capítulo IV.D., referido a las Áreas de Restricción y Límite de Extensión Urbana Sector Sur-Oriente, la Memoria Explicativa del PRMS señala que:

la extensión del área urbana metropolitana de Santiago en sentido Nor-Oriente, Oriente y Sur-Oriente, a través de las áreas urbanizables que presentan las comunas de borde, desde la comuna de Lo Barnechea hasta la comuna de Puente Alto, se enfrenta con un límite reconocible y de gran presencia, dado por el cordón de cerros que conforman la precordillera y Cordillera Andina.

Dentro de las áreas de restricción, este cordón montañoso corresponde a un área de Valor Natural, específicamente de Preservación Ecológica; sobre la cota 900 m.s.n.m para las comunas de la Reina, Peñalolén, La Florida, Puente Alto y cota 1.000 m.s.n.m. para las comunas de Las Condes, Lo Barnechea y Vitacura ${ }^{3}$.

1 Artículo 35 del Decreto con Fuerza de Ley 458 de 1975, Ley General de Urbanismo y Construcción, Ministerio de Vivienda y Urbanismo.

2 Ibid.

3 Énfasis añadido. 
Conforme al artículo 2.2.1 del PRMS, se entiende por “Área Urbana Metropolitana” «aquel terreno circunscrito por el Límite de Extensión Urbana y que por su capacidad, se destina a acoger el crecimiento de la población urbana y sus actividades.».

Por su parte, el artículo siguiente indica que se entiende por "Área Restringida o Excluida al Desarrollo Urbano" «aquel territorio de las comunas comprendidas en el Plan, que no ha sido definido como Área Urbana Metropolitana y en el que sólo se acepta el emplazamiento de las actividades urbanas expresamente señala en el Título $8^{\circ}$ de esta Ordenanza».

Así, para la Memoria Explicativa, el Área de Preservación Ecológica -donde está prohibida la construcción- de las comunas de Las Condes, Lo Barnechea y Vitacura se sitúa a partir de la cota 1.000 m.s.n.m., donde se prohíbe la construcción urbana. Ése es el límite urbanizable en dichas comunas.

Sin embargo, en el Plano de Zonificación de Uso de Suelos, el trazado del Área de Preservación Ecológica se graficó de manera distinta a la manifestada en la Memoria Explicativa: el trazado se dibujó en la cota 900 m.s.n.m., en lugar de la cota 1.000 m.s.n.m.

En efecto, el plano graficó erróneamente una porción emplazada entre las quebradas Los Almendros y San Ramón con una cota 900 m.s.n.m. (siendo que en la realidad ese límite le corresponde a las comunas de La Reina, Peñalolén y La Florida). Es decir, hubo un error de transcripción de la Memoria Explicativa al Plano de Zonificación de Usos de Suelo, al haber considerado el límite comunal entre las comunas de La Reina y Las Condes la quebrada Los Almendros en lugar de la quebrada San Ramón.

Entonces, el problema consiste en decidir qué documento tiene preferencia interpretativa-o si se prefiere, mayor jerarquía normativa-si en un Plan Regulador Metropolitano existen discrepancias entre la Memoria Explicativa y el Plano respectivo.

\section{Para la Contraloría General de la República el plano prima sobre la memoria explicativa}

Pues bien, en su Oficio No 12.516, de 2017, la Contraloría General de la República citó la Memoria Explicativa del PRMS, específicamente su letra b. Sector Oriente, del punto D. "ÁREAS DE RESTRICCIÓN Y LIMITE DE EXTENSIÓN URBANA", respecto a que «[d]entro de las áreas de restricción, este cordón montañoso corresponde a un Área de Valor Natural, específicamente de Preservación Ecológica; sobre la cota 900 m.s.n.m. para las comunas de La Reina, Peñalolén, La Florida, Puente Alto y cota 1.000 m.s.n.m. para las comunas de Las Condes, lo Barnechea y Vitacura».

Además, sostuvo que «la Memoria Explicativa de un plan regulador intercomunal contiene aspectos conceptuales y técnicos que justifican las decisiones de planificación $n^{4}$ adoptada

4 Énfasis añadido. 
en relación con los elementos estructurantes territoriales y funcionales pertinentes, lo que, en la especie, se advierte que revisten un carácter general».

Es decir, la intención del planificador se encuentra en la Memoria Explicativa, ya que tal como lo dice el dictamen «justifica las decisiones del planificador».

Además, sostuvo que el PRMS está compuesto por dos planos-como instrumentos de planificación territorial-«el RM-PRM 93/1A6, que observa que el límite de extensión urbana de la comuna de Las Condes sigue su gran mayoría la cota 1.000 metros sobre el nivel del mar, con excepción del tramo por el que se consulta -que se extiende aproximadamente desde la quebrada Los Almendros hasta la quebrada San Ramón- que sigue a la cota de 900 metros sobre el nivel del mar» y el plano RM-PRM-92/A1 corroboró dicha situación.

Por tal motivo, la jurisprudencia administrativa contenida en el dictamen $\mathrm{N}^{\circ} 39.397$, de 1997, sostuvo que «[...] es indispensable atenerse al sentido general de la normativa, reflejado en el instrumento en su integridad y no solo en alguna de sus partes, es decir, ha de recurrirse a la intención del planificador».

No obstante, el referido dictamen $\mathrm{N}^{0} 12.516$, de 2017, realizó diversas apreciaciones:

- En primer lugar, para la Contraloría, el hecho de que la situación se repita en el dibujo de dos planos descartaría que exista un error de graficación.

- En segundo lugar, y pese a que la Memoria Explicativa contiene los aspectos conceptuales y técnicos de la planificación, éstos se expresan gráficamente y con un mayor nivel de detalle en los planos.

- En tercer término, la intención de "correr" el límite del sector de la 900 a la cota 1.000 implicaría marginar de protección a un importante sector de la base del cordón montañoso, opinión que la transforma en un planificador urbano.

- Finalmente, según la Contraloría, corroboraría lo expuesto el hecho de que el Plan Regulador Comunal de Las Condes-promulgado por la resolución No 8, de 1995 del Gobierno Regional Metropolitano-también sitúa los tramos en cuestión en la singularizada en la cota 900. En este punto, la Contraloría no repara en el hecho de que la Municipalidad no tenía ninguna posibilidad legal de que el Plan Regulador Comunal de Las Condes no fuera fiel al PRMS, aunque éste contuviera un error. En los hechos, el PRMS actúa como "ley pantalla" del plan regulados comunal citado.

Por tales razones, la Contraloría concluye que para los efectos de determinar el límite de 
la extensión urbana de la comuna de Las Condes se debe seguir lo graficado en los planos concernientes del PRMS.

Posteriormente, mediante el oficio $\mathrm{N}^{\mathrm{o}} 38.279$, de 2017, la Contraloría reiteró el dictamen $\mathrm{N}^{\mathrm{o}} 12.516$, sin dar nuevos argumentos que los ya expresados. Sólo nos interesa destacar dos afirmaciones. La primera es que reiteró que debía mantenerse el límite en la cota 900, pues de fijarlo en la cota 1.000 «implicaría, en la especie, excluir a los terrenos de que se trata de la protección propia de una zona de preservación ecológica que los ha amparado desde la aprobación del PRMS, que data del año 1994». No deja de llamar la atención esta postura, pues es más bien una decisión de mérito que corresponde al planificador urbano.

Además, entre la cota 900 y la cota 1.000, en las tres comunas involucradas existen innumerables construcciones -varios colegios, universidades, clínicas, cines, supermercados y viviendas-, ninguna de las cuales ha sido objetada. Si la Contraloría fuera consistente, debería ordenar a las municipalidades que dispusieran la demolición de esas edificaciones o colocar los antecedentes a disposición del Consejo de Defensa del Estado para que éste sea el que formule judicialmente dicha petición.

La segunda afirmación que nos llama la atención es que a su juicio, su oficio no transgrede garantías constitucionales, pues «la Carta Fundamental y la legislación [le] encomiendan ejercer el control de la juridicidad de los actos de la Administración y en tal virtud, entre otras atribuciones, se le faculta para emitir pronunciamientos en derecho, la obligatoriedad de estos emana en último término de la norma interpretada y de los preceptos constitucionales y legales que sustentan esas opiniones jurídicas, desde el momento que este Organismo de Control nada agrega a esa disposición, limitándose a efectuar un juicio declarativo al respecto». Aunque aceptáramos la tesis de que el estar dotado de potestades supone que con su ejercicio la autoridad actúa legítimamente, parte importante de los autores que postulan la tesis subjetiva de la responsabilidad civil extracontractual del Estado admiten que en determinadas circunstancias éste es responsable por hechos lícitos ${ }^{5}$. Pero ésa es otra historia.

A nuestro juicio es un error conceptual dar una preferencia a los Planos por sobre la Memoria Explicativa. Existen poderosos argumentos que nos llevan a pensar de esta manera y a continuación los explicaremos.

\section{No es exacto que en la zona en cuestión exista un cordón montañoso}

El dictamen $\mathrm{N}^{\mathrm{o}} 12.516$ comete varios errores. El primero es geográfico: afirma que en el área en cuestión existe un pretendido "cordón montañoso". Indica que el límite urbaniza-

5 Por ejemplo, Pedro Pierry, Urbano Marín, Raúl Letelier, Juan Carlos Ferrada y nosotros mismos, entre otros. 
ble «se dibuja detalladamente en dos planos distintos siguiendo la cota 900 [...], abarcando un área conformada por la base del cordón montañoso, ubicado en esa zona, la que junto con aquel, corresponden a un área de valor natural» ${ }^{6}$.

Sin embargo, en el área comprendida entre las cotas 900 y 1.000 m.s.n.m. nadie ha sido capaz de encontrar cordón montañoso alguno, ni menos que éste sea un "área de valor natural".

Por el contrario, es una zona de topografía más suave que la existente en el sector comprendido entre las cotas 800 y 900 m.s.n.m.

El error parece provenir del hecho que el dictamen $\mathrm{N}^{\circ} 12.516$ aplicó (copió) el dictamen No 39.397, de 1997, que alude a la existencia de un "gran cordón montañoso". Sin embargo, este último oficio se refiría al límite urbanizable en la comuna de Huechuraba, donde en la cota 600 comienza un cordón de cerros de innegable necesidad de ser preservado ecológicamente. De allí que al redactar el dictamen No 12.516 la Contraloría reprodujo tanto el criterio jurídico del oficio anterior, como la topografía que le sería de fundamento. De allí que en virtud de su potestad dictaminante la Contraloría haya descubierto - antes que cualquier topógrafo- la existencia de un "importante cordón montañoso" digno de protección ambiental que atraviesa las tres comunas a que nos estamos refiriendo ${ }^{7}$.

\section{No es efectivo que los planos tengan un mayor nivel de detalle}

Por una parte, la Contraloría sostiene que debe darse preferencia a los planos pues éstos contendrían un "mayor nivel de detalle". Esto no es efectivo. No existe ningún elemento geográfico que motive hacer una precisión en una materia que está absolutamente clara en la memoria.

En ninguna de sus partes ni la Ley General de Urbanismo y Construcciones ${ }^{8}$ (en lo que sigue, LGUC) ni la Ordenanza General de Urbanismo y Construcciones (en adelante, OGUC o simplemente la Ordenanza) permiten sostener una afirmación como ésa.

En efecto, el artículo 2.1.8 de la Ordenanza define la Memoria Explicativa diciendo que ella «deberá contener los aspectos conceptuales y técnicos que justifican las decisiones de planificación adoptadas en relación con los elementos estructurantes territoriales y funcionales de la intercomuna, tales como: objetivos, fundamentos y metodología empleada,

6 Énfasis añadido.

7 Naturalmente, el oficio 38.278 de 20I7, guardó silencio sobre el imaginario cordón montañoso, privándolo de protección ecológica.

8 Decreto con Fuerza de Ley $45^{8}$ de 1975, Ley General de Urbanismo y Construcción, Ministerio de Vivienda y Urbanismo. 
incluyendo los estudios y antecedentes técnicos que sirvieron de base a la formulación

del diagnóstico y los antecedentes necesarios para dar cumplimiento a la Ley de Bases Generales del Medio Ambiente».

En tanto, los Planos deben limitarse a expresar gráficamente los contenidos del Plan. Vale decir, la Memoria Explicativa da cuenta de los aspectos conceptuales y técnicos que justifican las decisiones de planificación adoptadas en relación con los elementos estructurantes territoriales y funcionales de la intercomuna.

Resulta evidente entonces que la Memoria Explicativa es la que contiene un mayor nivel de detalle que los planos y que estos últimos sólo deben graficar los contenidos del plan.

No existe ninguna razón ni jurídica ni técnica que permita sostener que los planos tendrían un "mayor nivel de detalle" que la Memoria Explicativa y consecuentemente una preferencia interpretativa.

Por otra parte, el argumento es absurdo desde otra perspectiva. Bien es sabido que la Constitución Política se caracteriza por un grado importante de generalidad y abstracción. Ésta se desarrolla con más detalle en la ley y, como ésta tampoco puede contemplar todas las hipótesis posibles, es ejecutada mediante un reglamento.

Es decir, los reglamentos se caracterizan por tener un significativo mayor nivel de detalle que la propia Carta Fundamental.

De seguir la teoría de la Contraloría General de la República de dar preferencia al instrumento que tenga un "mayor nivel de detalle", para ser consistente, necesariamente el reglamento tendría una jerarquía superior a la de la Constitución Política de la República.

\section{La jerarquía de los instrumentos que integran el PRMS}

El PRMS, como todo documento de esta naturaleza, se compone de tres instrumentos:1) la Memoria Explicativa, que es aquel instrumento de planificación territorial, que contiene los objetivos, metas y programas del Plan Regulador Intercomunal, 2) una Ordenanza, que contiene las disposiciones reglamentarias pertinentes, y 3) los Planos, que expresan gráficamente las disposiciones sobre zonificación general, equipamiento, relaciones viales, áreas de desarrollo prioritario, límites de extensión urbana, densidades, entre otros ${ }^{9}$.

$8 \quad$ Ver supra nota I 
Pues bien, entre los instrumentos del Plan existe una relación de jerarquía, en términos tales que la Memoria Explicativa ocupa un nivel superior respecto de los otros instrumentos-ordenanza y planos-, los cuales deben subordinarse a ella.

Siendo ello así, en caso de contradicción en su contenido-como ocurre con cualquier instrumento jurídico-debe darse primacía a la de superior jerarquía.

Sin embargo, el dictamen $\mathrm{N}^{\mathrm{o}}$ 12.516, de 2017, contiene una aseveración del todo diferente: «En este contexto, es menester consignar que la memoria explicativa de un plan regulador intercomunal contiene los aspectos conceptuales y técnicos que justifican las decisiones de planificación adoptadas en relación con los elementos estructurantes territoriales y funcionales pertinentes, los que, en la especie, se advierte que revisten un carácter general, y que, por su parte, es en los planos donde se expresan gráficamente-y, también en la especie, con un mayor nivel de detalle-, los contenidos del atingente plan $\gg^{10}$.

Es decir, para el dictamen, priman los planos por ser instrumentos de detalle, por sobre la Memoria, por ser de carácter general.

Sin embargo, podemos hacer un ejercicio intelectual que puede demostrar lo equivocado de ese razonamiento.

Si analizamos la Constitución Política podemos apreciar que como todo texto de esa naturaleza, contiene un elevado grado de generalidad y abstracción, caracterizándose, como dice Robert Alexy ${ }^{11}$, por su textura abierta y, como indica H. L. Hart ${ }^{12}$, por el intenso uso de conceptos jurídicos indeterminados. Vale decir, es un instrumento general que se desarrolla en instrumentos de inferior jerarquía.

En el otro extremo, los reglamentos se caracterizan por su elevado nivel de especificidad y de concreción y por un alto nivel de detalle y singularización de las conductas que regulan. Es decir, son un instrumento especial por su alto nivel de desagregación.

Vistas así las cosas, así como la Constitución Política es general, la Memoria Explicativa también es general; así como los planos son detallados, el reglamento también es detallado.

Sin embargo, nadie se atrevería a sostener que por estar dotado de "un mayor nivel de detalle", el reglamento pudiera tener una jerarquía superior a la Constitución.

10 Énfasis añadido.

11 Robert Alexy, La doble naturaleza del derecho (Madrid: Trotta, 2016).

12 H. L. A. Hart, El concepto del derecho (Buenos Aires: Abeledo-Perrot, I995), I6oss. 
Ese es el equívoco en que, desde el punto de vista jerárquico, incurre el dictamen $\mathrm{N}^{\circ} 12.516$.

\section{El carácter administrativo de la Memoria Explicativa}

Para la confección del PRMS, del Plan Regulador Intercomunal (en adelante, PRI) y del Plan Regulador Comunal (en lo que sigue, PRC) se requieren tres instrumentos complementarios $^{13}$. Éstos son la Memoria Explicativa, una ordenanza y los planos, los cuales no pueden proseguir sin la existencia de los otros.

En efecto, el artículo $1^{\circ}$ del PRMS, ubicado en el Título I, "Disposiciones Generales" indica que «El Plan Regulador Metropolitano de Santiago, en adelante el Plan Metropolitano, está conformado por la presente Ordenanza, los Planos RMPRM921.A, RMPRM921.A.1., RMPRM921.A.2., RMPRM931.A.4., RMPRMS031.A.5./1.A.5/70, RMPRM931.A.6., RMPRM921.B, Plano RMPRM93T, Plano RMPRM95CH.1.A., Plano RMPRM99 CH.2.B(*)., Plano RMPRM95.CH.1.C., Plano RMPRMS15/98, Plano RMPRM 01CH.1.B/22(*)1, la Memoria Explicativa, que le complementan y que para los efectos de su aplicación constituyen un solo cuerpo legal» ${ }^{14}$.

El artículo 35 de la LGUC señala que el Plan Regulador Intercomunal estará compuesto de:

a) Una Memoria Explicativa, que contendrá los objetivos, metas y programas de acción;

b) Una Ordenanza, que contendrá las disposiciones reglamentarias pertinentes, y

c) Los planos, que expresen gráficamente las disposiciones sobre zonificación general, equipamiento, relaciones viales, áreas de desarrollo prioritario, límites de extensión urbana, densidades, etc. Para los efectos de su aprobación, modificación y aplicación, estos documentos constituyen un sólo cuerpo legal.

Además, el artículo 42 sostiene que el Plan Regulador Comunal estará compuesto por:

a) Una Memoria Explicativa, que contendrá los antecedentes socio-económicos; los relativos a crecimiento demográfico, desarrollo industrial y demás antecedentes técnicos que sirvieron de base a las proposiciones y los objetivos, metas y prioridades de las obras básicas proyectadas;

13 Artículos 35 y 47 del Decreto con Fuerza de Ley $45^{8}$ de I975, Ley General de Urbanismo y Construcciones, Ministerio de Vivienda y Urbanismo..

14 Énfasis añadido. 
b) Un estudio de factibilidad para ampliar o dotar de agua potable y alcantarillado, en relación con el crecimiento urbano proyectado, estudio que requerirá consulta previa al Servicio Sanitario correspondiente de la Región;

c) Una Ordenanza Local que contendrá las disposiciones reglamentarias pertinentes, $y$

d) Los planos, que expresan gráficamente las disposiciones sobre uso de suelo, zonificación, equipamiento, relaciones viales, límite urbano, áreas prioritarias de desarrollo urbano, etc. Para los efectos de su aprobación, modificación y aplicación, estos documentos constituyen un solo cuerpo legal.

Es decir, la propia LGUC les otorga una importancia a los instrumentos de planificación sobre los cuales se basan los Planes Reguladores.

Siendo ello así, de la sola lectura de dichos preceptos se desprende que en la Memoria Explicativa se fijan los antecedentes socio-económicos; los relativos a crecimiento demográfico, desarrollo industrial y las metas, objetivos y programas de acción. Todo esto sirve de base para la confección de los demás instrumentos. Vale decir, la Memoria Explicativa es el instrumento que retrata la intención del planificador, y por tanto, sirve de guía para la confección de los planos, los que a su vez sirven de base para finalmente confeccionar la ordenanza.

Resulta imposible que todos los instrumentos se construyan al mismo tiempo, y por lo tanto existe un orden de prelación para la confección de cada uno de ellos, a fin de dar lugar a un cuerpo legal armónico entre todos y cada uno de esos instrumentos.

En el mismo sentido, el artículo 2.1.8 de la OGUC confirma lo establecido en la LGUC, respecto de que el PRI debe estar compuesto por:

1. Memoria Explicativa, que deberá contener los aspectos conceptuales y técnicos que justifican las decisiones de planificación adoptadas en relación con los elementos estructurantes territoriales y funcionales de la intercomuna, tales como: objetivos, fundamentos y metodología empleada, incluyendo los estudios y antecedentes técnicos que sirvieron de base a la formulación del diagnóstico y los antecedentes necesarios para dar cumplimiento a la Ley de Bases Generales del Medio Ambiente ${ }^{15}$.

2. Ordenanzas, que contendrá las disposiciones reglamentarias pertinentes a este nivel de planificación urbana intercomunal.

3. Planos, que expresen gráficamente los contenidos del Plan.

Énfasis añadido. 
Es más, en múltiples artículos, la Ordenanza se refiere a la Memoria Explicativa como un requisito de configuración de determinados instrumentos o de su importancia como documento de validez en distintas instancias administrativas, como por ejemplo en su artículo 2.1.9 ${ }^{16}$, en relación al Plan Regulador Intercomunal, en su artículo 2.1.10 ${ }^{17}$, en relación al

16 Éste indica:

El Plan Regulador Intercomunal será confeccionado por la Secretaría Regional Ministerial de Vivienda y Urbanismo respectiva, con consulta a las Instituciones que integran la Administración del Estado que se estime conveniente y su aprobación deberá ajustarse al siguiente procedimiento.

[...] Dichos Planos, junto con un ejemplar de la Memoria Explicativa, de la Ordenanza y del Diario Oficial en que se hubiere publicado la Resolución aprobatoria del Gobierno Regional, serán archivados en el Gobierno Regional; una copia oficial de dichos documentos será archivada en la División de Desarrollo Urbano del Ministerio de Vivienda y Urbanismo, otra en la Secretaría Regional Ministerial de Vivienda y Urbanismo respectiva y otra en el Conservador de Bienes Raíces correspondiente.

17 El cual indica:

El Plan Regulador Comunal será confeccionado, en calidad de función privativa, por la Municipalidad respectiva, y estará conformado por los siguientes documentos:

I. Memoria Explicativa que contenga, al menos, el diagnóstico de la totalidad del territorio comunal o del área afecta a planificación e identifique:

a. Los centros urbanos de la comuna, indicando su tamaño poblacional y sus tendencias estimadas de crecimiento.

b. Las vías estructurantes, en especial las vías colectoras y de servicio, indicando su relación con los caminos nacionales,

c. las vías expresas y troncales, definidas en la planificación urbana regional e intercomunal, respectivamente.

d. Las principales actividades urbanas de la comuna, con una apreciación de sus potencialidades.

e. El fundamento de las proposiciones del Plan, sus objetivos, metas y antecedentes que lo justifican, en base a los siguientes estudios especiales:

f. Estudio de Capacidad Vial, de las vías existentes y proyectadas, para satisfacer el crecimiento urbano en un horizonte de, al menos, io años.

g. Estudio del equipamiento comunal, que permita definir áreas para su desarrollo y expansión, cumpliendo los porcentajes mínimos de superficie urbana comunal definidos por la planificación urbana intercomunal.

h. Estudio de Riesgos y de Protección Ambiental, con sus respectivas áreas de restricción y condiciones para ser utilizadas de acuerdo a las disposiciones contempladas en los artículos 2.I.I7. y 2.I.I8. de este mismo Capítulo.

i. Los inmuebles declarados Monumento Nacional y las Zonas Típicas.

j. Los inmuebles o zonas de conservación histórica, incluyendo la fundamentación de cada caso. 
Plan Regulador Comunal, en su artículo 2.1.11 ${ }^{18}$, en relación a los procedimientos para la elaboración y aprobación de los Planes Reguladores Comunales y la información que la Municipalidad le debe entregar a sus vecinos antes de aprobar dicho proyecto, en su artículo 2.1.15 ${ }^{19}$, en relación a los "Planes seccionales", respecto a los casos en que no exista un plan Regulador Comunal vigente, se debe aprobar los Planes Seccionales, siguiendo los mismos procedimientos establecidos para la aprobación de los Planes Reguladores Comunales, y en su artículo 2.1.16 ${ }^{20}$, en relación al "Límite urbano".

En atención a lo anterior, podemos desprender la importancia y el orden de prelación y de temporalidad que existen entre los instrumentos que sirven de base para la confección de los Planes Reguladores.

18 Éste establece:

El procedimiento para la elaboración y aprobación de los Planes Reguladores Comunales se regirá por lo dispuesto en los incisos siguientes. El proyecto de Plan Regulador Comunal será preparado por la Municipalidad respectiva. Elaborado el proyecto, el Concejo, antes de iniciar su discusión, deberá: I. Informar a los vecinos, especialmente a los afectados, acerca de las principales características del Instrumento de Planificación Territorial propuesto y de sus efectos, señalando los criterios adoptados respecto de cada uno de los contenidos del Plan Regulador Comunal señalados en el artículo 2.I.Io. de esta Ordenanza General.

Tal información deberá entregarse, al menos, mediante carta certificada a las organizaciones territoriales legalmente constituidas que estén involucradas y, a través de un aviso de prensa en un medio de amplia difusión en la comuna, se pondrá en conocimiento de los vecinos que dicha información, acompañada de la Memoria Explicativa, estará a su disposición para su retiro gratuito, en el lugar que allí se indique. En este mismo aviso se indicará el lugar y fecha en que se realizarán las audiencias públicas a que se refiere el número siguiente.

19 El cual dice:

En los casos a que se refiere el inciso segundo del artículo ${ }_{4}^{6}$ de la Ley General de Urbanismo y Construcciones, en que no exista Plan Regulador Comunal vigente, se podrán aprobar Planes Seccionales, utilizando el procedimiento establecido para la aprobación de los Planes Reguladores Comunales. Los Planes Seccionales de que trata este artículo consistirán en una Memoria Explicativa básica, en una ordenanza local que fije las condiciones mínimas de uso de suelo, de edificación y del trazado vial y en uno o más planos que grafiquen lo anterior. En los casos a que se refieren los incisos primero y segundo del artículo 72 de la Ley General de Urbanismo y Construcciones, deberá confeccionarse un Plan Seccional de Zona de Remodelación, el que constará de los siguientes antecedentes: ı. Catastro de la situación existente de la zona escogida en base a uno o más planos que grafiquen lo siguiente: a) Trazados viales, líneas oficiales y líneas de edificación existentes. b) Características de la edificación existente con su volumetría, coeficientes y densidades. c) Usos de suelo existentes. 2. Memoria Explicativa, que contenga los fundamentos de la proposición. 


\section{El reconocimiento que la doctrina nacional le ha dado a la Memoria Explicativa}

Existe escasa literatura nacional que haya analizado esta materia. Sólo de manera tangencial existen algunos trabajos que tímidamente han abordado el tema de la prelación de los instrumentos que componen los Planos Reguladores, es decir, sólo se ha limitado a reproducir el contenido de la Ley y de la Ordenanza.

Existe un completo trabajo denominado "Régimen Jurídico de los Planes Reguladores" de Gabriela Soto ${ }^{21}$, que se refiere de forma más acabada a los instrumentos de planificación que se requieren para la configuración de los planos reguladores y que resulta pertinente traer a colación.

En lo que nos interesa, nos avocaremos a lo que esta autora plantea respecto al rol y objetivo de la Memoria Explicativa.

En primer lugar, Soto sostiene acertadamente que los objetivos de cada plan intercomunal o metropolitanos, tanto los generales como los específicos los encontramos en su memoria explicativa, que es uno de los documentos que los conforman, por ejemplo, en la memoria explicativa del Plan Regulador Metropolitano de Santiago se puede ver como los planificadores desarrollan los objetivos generales del Plan en función de los que hemos mencionado.

En segundo término, explica la composición del PRMS, indicando que éste se conforma con tres documentos, una Memoria Explicativa, una Ordenanza y los Planos, y que todos ellos constituyen un solo cuerpo legal.

En ese mismo sentido, advierte que la LGUC sólo se refiere a la Memoria Explicativa en términos generales, es decir, se limita a señalar en qué consiste ese documento, sus ob-

20 Según éste:

Para la aprobación de un límite urbano en comunas que no cuenten con él, o la modificación del límite existente, se requerirá la presentación de los siguientes documentos: r. Memoria Explicativa, que contenga los elementos técnicos necesarios para fundamentar su proposición. 2. Descripción de los puntos y tramos de la poligonal que corresponda al nuevo límite urbano. 3. Plano, que contenga su graficación. La proposición del nuevo límite urbano o la modificación del límite urbano existente, se someterá al mismo procedimiento contemplado para la tramitación y aprobación de un Plan Regulador Comunal, previo informe de la Secretaría Regional Ministerial de Agricultura, organismo que deberá emitirlo dentro del plazo de I5 días, contado desde que le sea requerido por la Municipalidad. Vencido dicho plazo, se tendrá por evacuado sin observaciones.

21 Gabriela Soto Bustos, "Régimen Jurídico de los Planes Reguladores” (memoria de licenciatura, Universidad de Chile, I996). 
jetivos, sus metas y los programas de acción, a diferencia de la Ordenanza, que le da un mayor desarrollo al contenido de la Memoria Explicativa ${ }^{22}$.

La OGUC precisa que la Memoria Explicativa debe contener el diagnóstico del área en estudio, debiendo considerar, entre otros aspectos, la capacidad de la infraestructura sanitaria, vial y energética para el crecimiento urbano por extensión y densificación, la suficiencia del sistema de equipamiento urbano y los impactos de localización de actividades productivas ${ }^{23}$.

En ese sentido, la autora agrega que:

Hasta 1993, la Ordenanza, como ya se ha señalado, en este punto sólo indicaba que la memoria debía contener el análisis y diagnóstico del área en estudio para luego referirse a las demás exigencias de aquel documento, establecer objetivos, metas, etc.. Este precepto en su actual redacción se debe a la modificación efectuada por D.S. No 101 de 1993 del MINVU. Sobre el fundamento de las modificaciones se expresó en su oportunidad que las innovaciones en esta materia respondían a la necesidad de que los Planes Reguladores Comunales e Intercomunales contuvieran la realidad de la infraestructura de la comuna a fin de evitar problemas a futuro. ${ }^{24}$

Es más, en el trabajo mencionado, la autora cita al Secretario Ministerial de Vivienda y Urbanismos de esa época, don Jaime Silva, quien explica el fundamento real de la reforma a la Ordenanza, que como apreciaremos le entrega una importancia mayor a la Memoria Explicativa por sobre el Plano. Dicha autoridad expresó que «una condición fundamental es que lo que se dibuja tenga su soporte en la infraestructura. Muchas veces hay diseños espectaculares pero que no han tomado en cuenta la realidad circundante» ${ }^{25}$.

En definitiva, el Secretario Ministerial jerarquizó los instrumentos que sirven para conformar el Plan Regulador, en términos tales que, si bien son instrumentos independientes, existe una relación de jerarquía entre cada uno de ellos.

En tercer lugar, Soto se refiere al rol de la Memoria, y sustenta su trabajo en la Política Nacional de Desarrollo Urbano del Ministerio de Vivienda y Construcciones, en cuanto

\footnotetext{
22 Ibid., 9o.

23 Ibid.

24 Ibid., 9I.

25 Jaime Silva en entrevista a El Mercurio (Santiago), 23 de diciembre de 1993, 8, citado en Gabriela Soto Bustos, "Régimen Jurídico de los Planes Reguladores" (memoria de licenciatura, Universidad de Chile, I996), 9 I.
} 
se considerará presente y activa durante todo el período de aplicación del Plan y a ella debe acudir la autoridad en caso de dudas sobre su forma de implementación (por lo tanto, además de fundamento sirve a la interpretación y aplicación del Plan), en igual forma se señala que los fundamentos de toda modificación del Plan deberán expresarse a través de un complemento de la memoria el cual se referirá en forma expresa a los planteamientos de la memoria original.

En efecto, se debe acudir a la memoria, en caso de (i) duda sobre su implementación; (ii) interpretación del Plan; y (iii) aplicación del Plan.

Entonces, indica de manera fundada y acertada que al existir discordancia entre los instrumentos de planificación del Plan Regulador tanto Intercomunal como Comunal, o más precisamente errores de graficación entre ellos, las autoridades se deben dirigir obligatoriamente a la Memoria Explicativa, que es la que contiene el fundamento de la confección del Plan.

En esa misma línea se ha pronunciado Osvaldo Vargas Zincke, Jefe de la División de Infraestructura y Regulación de la Contraloría General, quien en su dictamen $\mathrm{N}^{\circ}$ 66.458, del año 2013, indicó que «[e]n la Ordenanza se reconocen "Áreas con peligro de ser afectadas por fallas geológicas ARR-6", pero en el Plano únicamente se grafican líneas sin superficie relacionada, lo que no se condice con lo expresado en la página 47 de la Memoria Explicativa en cuanto propone un perímetro de $1 \mathrm{~km}$. alrededor de la falla».

De este modo, Vargas resalta que, al momento de interpretar los instrumentos que componen los Planos Reguladores, la Memoria Explicativa tiene un carácter normativo superior al cual deben ajustarse los planos, lo que permite velar por su coherencia.

A mayor abundamiento, una reciente doctrina nacional ha establecido que dentro de los documentos que conforman el PRC se encuentra de forma primordial la Memoria Explicativa, estableciendo que «Constituye un sustrato imprescindible a la hora de aplicar e interpretar el respectivo plan. [...] En el fondo, constituye un verdadero diagnóstico de la situación general del territorio comunal, además de los objetivos y metas a lograr (artículo 42 de la L.G.U.C y 2.1.10. de la O.G.U.C)» ${ }^{26}$.

Dicho lo anterior, no cabe más que concluir que para interpretar el Plan Regulador-Metropolitano o comunal-necesariamente nos debemos dirigir primeramente a la Memoria Explicativa.

26 Patricio Figueroa Velasco y Juan Figueroa Valdés, Urbanismo y Construcción, Colección Tratados y Manuales, 2a ed. (Santiago: Thomson Reuters, 20I6), $\mathrm{I}_{4} 6$. 
La doctrina también se ha pronunciado sobre la importancia de la Memoria Explicativa. En este sentido los profesores Patricio Figueroa Velasco y Juan Figueroa Valdés, han establecido que: «la Memoria Explicativa constituye un sustrato imprescindible a la hora de aplicar e interpretar el respectivo plano. En ella se contendrán los antecedentes socio-económicos; los relativos al crecimiento demográficos, desarrollo industrial y demás antecedentes técnicos que sirvieron de base a las proposiciones, y los objetivos, metas y prioridades de las obras básicas proyectadas». ${ }^{27}$

Además, el profesor Enrique Rajevic también se ha referido al tema argumentando que:

Existen, entonces, herramientas suficientes para poder verificar la constitucionalidad y legalidad de la planificación, con lo que el particular puede revisar si se ajusta o no a derecho una modificación de la ordenación territorial. Mediante este "arsenal jurídico" los jueces pueden efectuar un control máximo de la decisión administrativa en materia urbana. Criterios para enjuiciarla serán el que las decisiones sean coherentes con la Memoria Explicativa del Plan-una suerte de ratio interna que debiera recorrerle de punto a cabo-, que la planificación sea racional y proporcional en relación a aquella y considere también la naturaleza de los predios urbanos (asunto fáctico) ${ }^{28}$

Es decir, este profesor confirma lo que hemos venido sosteniendo en cuanto a que el criterio que deben utilizar los jueces para ver la Constitucionalidad y legalidad de las decisiones administrativas (PRMS) es que sean coherentes con la Memoria Explicativa. En efecto, el autor ni siquiera menciona los demás instrumentos de planificación que conforman el PRMS.

\section{La jurisprudencia nacional}

Por otra parte, pronunciándose sobre causas que han involucrados a municipalidades afectas a la cota 1.000, los tribunales de justicia han reconocido explícita o implícitamente que ella fija el límite urbano. Jamás se ha planteado ni por el Fisco ni por otro interviniente, ni siquiera tangencialmente, que el límite pudiera ser la cota 900 m.s.n.m.

\section{La jurisprudencia de la Corte de Apelaciones de Santiago}

En el considerando séptimo de la causa rol No 466-2002, la Ilustrísima Corte de Apelaciones de Santiago analizó un recurso presentado por la Sociedad Civil San Juan de Krond-

27 Ibid., énfasis añadido.

28 Enrique Petar Rajevic Mosler, "La propiedad privada y los derechos adquiridos ante la planificación urbana”, Revista Chilena de Derecho 25, nº I (I998): Iıo. Énfasis añadido. 
stand en contra de la Municipalidad de Lo Barnechea, que había ordenado la destrucción de inmuebles que aquella había construido por sobre la cota 1.000 m.s.n.m. Esta Corte resolvió que:

De conformidad con el Plano Regulador Metropolitano de Santiago, los terrenos emplazados fuera de las áreas urbanizadas y urbanizables, que comprenden áreas de interés natural o paisajístico y/o presentan vegetación y fauna silvestre, cursos o vertientes naturales de agua, que constituyen un patrimonio natural o cultural, deben ser protegidos o preservados. En el caso de autos, el límite urbano lo define la cota mil en consecuencia, todo lo que se encuentre sobre dicha cota, es área de valor natural, esto es zona de preservación ecológica. Estas zonas de preservación ecológica, serán mantenidas en su estado natural para asegurar y contribuir al equilibrio natural y calidad del medioambiente como también para preservar el patrimonio paisajístico. En estas áreas se restringe su uso a los fines ya indicados, con las instalaciones y/o edificaciones mínimas e indispensables para su habilitación ${ }^{29}$.

En virtud de lo anterior, la Corte concluyó que la Sociedad aludida infringió la LGUC y el PRMS, por lo que estimó que el decreto alcaldicio de la Corporación de Lo Barnechea se ajustó a derecho.

Es decir, la Corte de Apelaciones de Santiago concluyó que en la comuna de Lo Barnechea el límite del área urbanizable es hasta la cota 1.000. En ninguna parte del juicio se sostuvo que el límite urbanizable era la cota 900, como erróneamente lo dibuja el plano en cuestión y como lo entiende la Contraloría. De hecho, en ninguna de sus partes la sentencia hace alusión alguna a la cota 900, ni tampoco reprocha que existan construcciones entre la cota 900 y la cota 1000, como de hecho las hay.

Por ende, y siguiendo el razonamiento judicial que analizamos, conforme al PRMS el área urbanizable en la comuna de Lo Barnechea es hasta la cota 1.000, y así lo ha permitido la Corte de Apelaciones de Santiago.

\section{La jurisprudencia de la Corte Suprema respecto de la Parcela El Cerro}

En otra causa, seguida esta vez ante la Corte Suprema ${ }^{30}$, el Fisco de Chile, a través del Consejo de Defensa del Estado (en adelante, CDE) solicitó, entre otras medidas: «2) Demoler las viviendas existentes sobre la cota 1.000 metros sobre el nivel del mar en la Parcela El Cerro» ${ }^{31}$, ubicadas en la comuna de Lo Barnechea.

29 Énfasis añadido.

30 SCS 25.720-20I4, del ro de diciembre de 20I5, redactada por la ministra Rosa Egnem.

31 Énfasis añadido. 
En su sentencia del ocho de agosto de dos mil catorce, la Corte de Apelaciones de Santiago había confirmado el fallo apelado de primera instancia, ordenando demoler las viviendas existentes sobre la cota 1.000 en la Parcela El Cerro, antes aludida.

Pues bien, resolviendo la materia en cuestión, la Corte Suprema indicó que «lo que sí se encuentra acreditado es que los daños materiales se provocaron por la construcción de caminos y viviendas sobre la cota $1.000 \gg^{32}$, precisando además que «atendidos los hechos claramente establecidos en la causa, fluye de modo nítido que en la sentencia atacada se ha dado correcta aplicación a la normativa que rige el caso».

Es decir, la Corte Suprema no cuestionó que entre las cotas 900 y 1000 se hubieran construido caminos y viviendas; lo que reprochó fue que ello se hubiera hecho sobre la cota 1.000, donde está situada el Área de Protección Ecológica.

Siguiendo el mismo razonamiento previo, tal como dijimos a propósito del fallo de la Corte de Apelaciones, ahora es la Corte Suprema la que según el PRMS reconoce que el área urbanizable es hasta la cota 1.000 m.s.n.m., en la comuna de Lo Barnechea, al igual que en las comunas de Vitacura y Las Condes, sin que resulte reprochable que se hayan realizado construcciones entre la cota 900 y la cota 1000.

De hecho, el Fisco de Chile, a través del CDE, también fue de la opinión de que el límite máximo es la cota 1000 y no la cota 900.

\section{La jurisprudencia de la Corte Suprema respecto de la Quebrada de Huallolén}

En una tercera causa, la misma Corte Suprema resolvió un recurso de casación en el fondo interpuesto por el CDE, en una causa contra la misma comuna de Lo Barnechea, por haber autorizado construcciones en la Quebrada de Huallalolén, ubicada en la parte norte del Estero El Arrayán, sector precordillerano de la misma comuna, por sobre la cota 1.000.

El CDE sostuvo que las construcciones se emplazan sobre la cota 1.000 m.s.n.m., que el PRMS, clasificó la zona como Área de Preservación Ecológica, y, en consecuencia, en ella se excluye el desarrollo urbano, permitiéndose sólo actividades que aseguren la permanencia de los valores naturales. Así restringe su uso a fines científicos, culturales, educativos, recreacionales, deportivos y turísticos, con las instalaciones y/o edificaciones mínimas e indispensables para su habilitación.

En este caso, conociendo de un recurso de casación en el fondo, la Corte Suprema resolvió:

Que finalmente, en relación a la pretendida excepción respecto a que a la Municipalidad de Lo Barnechea no le correspondería cautelar la situación de los 
lotes sobre la cota mil, cabe señalar que, aparte de ser una alegación nueva que sólo se hizo valer en estrados de esta Corte, de sus propias actuaciones aparece que ello no es así, puesto que no sólo no inspeccionó y fiscalizó debidamente, sino que además otorgó instrumentos a los ocupantes de los terrenos que permitió a éstos llevar a cabo gestiones para acceder a servicios como si fuera un loteo regular autorizado por la ley, tal como consta de fojas 76 de la copia del expediente de policía local traído a la vista, en que A.F.G. afirma haber obtenido un permiso municipal para instalar servicio eléctrico individual, acompañando incluso boletas de pago que así lo acreditan y el certificado de número al que dicho municipio asignó el numeral “20.415- D". por lo que no se entiende como, si dice que no le correspondía cautelar la situación de los lotes sobre la cota mil, otorgó certificados de número a lotes que no eran los originarios, tanto así que a continuación del número le colocó letras, aceptando con ello que conocía la existencia de subdivisiones, contribuyendo de esta manera al asentamiento humano en áreas de preservación ecológica, vulnerando con ello, el artículo 8.3.1.1 del Plan Regulador Metropolitano de Santiago, en cuanto éste dice que las áreas de preservación ecológicas serán mantenidas en estado natural, para asegurar y contribuir al equilibrio y calidad del medio ambiente, como asimismo, preservar el patrimonio paisajístico ${ }^{33}$.

Debemos hacer notar que el CDE no cuestionó a la Municipalidad de Lo Barnechea que haya autorizado construcciones por sobre la cota 900, como debería haberlo hecho si hubiese seguido el criterio del dictamen cuya reconsideración solicitamos, sino que, citando expresamente el PRMS, le reprochó haber otorgado permisos para construcciones por sobre la cota 1.000 .

Es más, el CDE nuevamente argumentó que el área urbanizable llegaba hasta la cota 1.000.

Del mismo modo, y tal como lo hizo en la sentencia que mencionamos en el numeral anterior, además del CDE, tampoco la Corte Suprema cuestionó que se hubiera dispuesto construcciones sobre la cota 900, sino que sobre la cota 1.000 .

Todos los casos mencionados previamente concluyeron que la prohibición que existe para la construcción urbana en las comunas de Lo Barnechea, Vitacura y Las Condes es a partir de la cota 1.000 m.s.n.m., por sobre la cual comienza la zona de preservación ecológica.

\section{La interpretación de la doctrina de referencia}

Ahora bien, la doctrina y la jurisprudencia española—como la principal fuente de referencia del derecho administrativo chileno-es la que ha realizado un análisis más profundo y

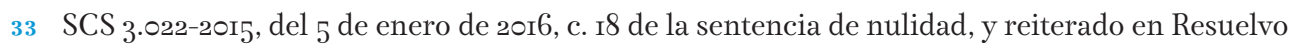
II, de su sentencia de reemplazo, de la misma fecha. 
exhaustivo sobre la importancia de la Memoria Explicativa como instrumento justificativo de los demás instrumentos de planificación, tales como los planos y la ordenanza.

Es del caso mencionar en primer lugar a la destacada profesora Eva Desdentado Daroca, quien, en su libro Discrecionalidad Administrativa y Planeamiento Urbanístico precisó que «La Memoria sirve de exposición de informaciones y explicaciones de los otros elementos constitutivos» ${ }^{34}$, y de justificación del modelo territorial elegido. Por esa razón, le da el carácter de "motivación de los planes. Finalmente, los planos de información tienen, como su propio nombre indica, una función principalmente informativa, aunque no carente de importancia, pues contienen parte de los hechos determinantes de la voluntad planificadora $^{35}$.

Agrega además que «La Memoria, es [...] un documento de carácter explicativo y justificativo, en el que la Administración planificadora expone los fines y objetivos que persigue la ordenación elegida y las razones que le han llevado a inclinarse por ese modelo territorial y no por otro» ${ }^{36}$.

Finalmente, Desdentado Daroca cita relevante jurisprudencia respecto a la Memoria Explicativa, sosteniendo que «En [los planes urbanísticos] la Memoria 'no es un documento accidental, que puede existir o no, sino una exigencia insoslayable de la Ley ${ }^{37}$. Los planes urbanísticos tienen que incorporar obligatoriamente la Memoria porque la Ley del Suelo la configura como un documento integrante esencial de los planes, en el que el planificador debe explicitar las razones que justifican y legitiman el uso, hecho de la profunda discrecionalidad de que dispone para dar contenido a los derechos de propiedad y elegir determinado modelo territorial ${ }^{38}$.

En segundo lugar, los destacados profesores Luciano Parejo y Eduardo García de Enterría en su clásica obra Lecciones de derecho urbanístico se refirieren de forma amplia a los

34 Eva Desdentado Daroca, Discrecionalidad Administrativa y Planeamiento Urbanístico. Construcción teórica y análisis jurisprudencial (Navarra: Aranzadi, I999), 362. En el mismo sentido, José María Boquera Oliver, en "Los componentes del plan de urbanismo”, Revista de derecho urbanístico y medio ambiente $\mathrm{I} 27$ (1992).

35 Ibid.

36 Ibid., $3^{62-363}$.

37 En este punto, la autora transcribe la STS RJ I992/3I4, de 20 de diciembre de I99I.

38 Desdentado, Discrecionalidad, 363 . Para profundizar en su tesis, la autora, en una nota a pie de esta misma página, recuerda que jurisprudencia considera que "la profunda discrecionalidad del planeamiento, producto normativo emanado de la Administración y que pese a ello está habilitado para regular el contenido del derecho de propiedad [...] explica la necesidad esencial de la Memoria como elemento fundamental" de carácter obligatorio. Ver, en este sentido, SSTS

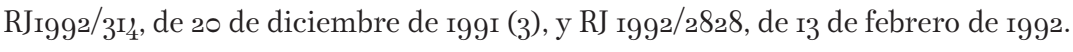


documentos fundamentales que se requieren para la configuración del Plan urbanístico. En lo que nos interesa, sostienen que los estudios que justifiquen la elección del modelo territorial adoptado que integran el documento se denominan "Memoria".

Éste es, en definitiva, «un documento en que deben contenerse todos los estudios en que se hayan basado y fundamentado las opciones de ordenación finalmente establecidas para llegar a conformar el "marco físico" o "modelo territorial" que constituye el objeto principal del Plan» ${ }^{39}$.

Es más, agregan que «la Memoria puede calificarse de "exposición de motivos", trasladando a este campo la técnica normativa usual. Tiene, por tanto, como mínimo un valor interpretativo del resto del contenido del Plan. Pero puede llegar a adquirir verdadera $y$ directa eficacia normativa en casó de insuficiencia o laguna del resto de las determinaciones $»^{40}$. Además, los autores precisan que la regulación de la Memoria está contenida en el apartado 1.0 del artículo 12 del Reglamento de Planeamiento para el desarrollo y aplicación de la ley sobre Régimen del Suelo y Ordenación Urbana, aprobado por el Real Decreto 2159/1978.

Dicho lo anterior, Parejo Alfonso y García de Enterría comparten lo sustentado por la jurisprudencia española. Expresan que la Sentencia del Tribunal Supremo del 16 de junio de 1977 es acertada en cuanto ella resuelve que «bastaría poner de manifiesto la circunstancia de que la referida Memoria, por lo mismo que es parte de ese todo, indiscriminado, constituido por el Plan, cuya obligatoriedad nadie discute [...], para afirmar, en acatamiento de la más estricta lógica, que si éste ha de ser vinculante en su totalidad, no podría tener eficacia esa obligatoriedad si no fuesen idénticamente obligatorias y vinculantes todas y

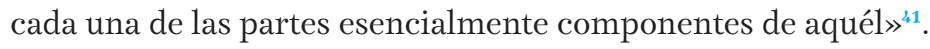

Dicho fallo concluye que:

lejos de poder ser considerada tan repetida Memoria como vehículo portador de simples motivaciones subjetivas reveladoras del personal propósito del gestor, constituye la auténtica causa, en sentido jurídico, determinante de un elemento esencial del negocio jurídico urbanístico, y, por lo mismo y en el propio orden de cosas, el expediente y una significativa potencia de auxilio a la hermenéutica para solucionar eventos, como el de autos, en que se pone de evidencia la disconformidad entre lo efectiva y materialmente realizado y lo jurídicamente

39 Luciano Parejo Alfonso y Eduardo García De Enterría, Lecciones de derecho urbanístico (Madrid: Civitas, I98I), 248 .

40 Ibid., 288. Énfasis añadido.

41 STS de i6 de junio de I977, en Parejo y García, Lecciones de derecho urbanístico, 288. 
realizable, por cierto imponiendo al intérprete la necesidad de que cualquier situación conflictiva dudosa haya de ser resuelta conforme a las previsiones que del contexto de la Memoria sean deducibles ${ }^{42}$.

En tercer lugar, en el libro El control de la discrecionalidad en el planeamiento urbanístico, de Javier Delgado Barrio, en especial citando a Tomás-Ramón Fernández, agrega que «la Memoria que debe presidir la documentación integrante de los planes no es, ni puede ser, un mero documento literario destinado a hacer bulto y a complementar formalmente una exigencia legal, sino, precisamente, el documento en el que-a partir del análisis del territorio, de sus problemas y sus posibilidades-se han de justificar las soluciones concretas que se eligen para la mejor ordenación de ese territorio» ${ }^{23}$.

En ese sentido, además es ilustrativa la historia de Eduardo García de Enterría sobre el litigio entre la Asociación de Vecinos de Orcasitas contra el Ayuntamiento de Madrid. En cuyo caso, el Tribunal Supremo dio la razón a los vecinos y declaró el carácter de vinculante de la memoria. Quien afirmaría esta doctrina «luego ha pasado a ser uno de los quicios de la teoría jurídica del Plan Urbanístico» ${ }^{44}$.

En cuarto lugar, los doctores en derecho Ricardo Santos Diez y Julio Castelao Rodríguez, en su libro Derecho Urbanístico, explicaron que, sobre la base de la legislación española ${ }^{45}$, los documentos con los que deben contar los Planes Generales para ser jurídicamente completos y susceptibles de aprobación, son los siguientes:

Memorias de información y justificativas de la ordenación que se establezca, con los estudios complementarios que sean precisos: deben justificar razonablemente las determinaciones normativas y gráficas del Plan General a partir de la información recogida y expresar la racionalidad de las decisiones adoptadas, de manera que tienen un valor normativo análogo a la Exposición de Motivos de una Ley, es decir, son fuentes de interpretación del deseo subyacente en la

42 Ibid., 288-289.

43 Javier Delgado Barrio, El control de la discrecionalidad en el planeamiento urbanístico, Colección Cuadernos (Madrid: Civitas, I993), 44 .

44 Eduardo García De Enterría, De montañas y hombres, Colección Austral (Madrid: Espasa-Calpe, I998), I57.

45 Contenida en el artículo I2.3 LS76, texto refundido de la Ley sobre Régimen del Suelo y Ordenación Urbana, aprobada por Real Decreto ${ }_{34} 4 / 1976$, de 9 de abril., y artículo $72 \cdot{ }_{4} \mathrm{LS}_{92}$, texto refundido de la Ley sobre Régimen del Suelo y Ordenación Urbana aprobada por Decreto Real Legislativo I/r992, de 26 de junio. La regulación estatal reglamentaria del "contenido y

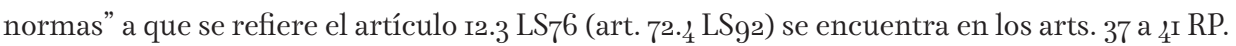


aprobación del Plan General. En esencia, la Memoria contiene la motivación del Plan General y delimita la discrecionalidad del planeamiento, evitando así su arbitrariedad. En caso de contradicción entre Memoria y Planos, la STS 22.05.91 afirma que debe prevalecer la Memoria ${ }^{46}$.

Además, en su sentencia del 8 de mayo del 2000, el Tribunal Supremo de España afirmó que «[1]a Memoria del Plan ofrece una suficiente indicación de las razones que aconsejan su modificación en términos que no permiten suponer que la potestad ejercitada tenga otra finalidad distinta que la adecuada ordenación urbanística de la manzana afectada».

En quinto término, Ramón López Sales, en su tesis doctoral "Régimen de las actuaciones urbanísticas sin título habilitante en la comunidad valenciana”, dirigida por el catedrático de Derecho Administrativo Jose Luis Blasco Díaz, concluyó que «[d]e todo lo anterior, en todo caso, se deriva la importancia de la memoria justificativa en el planeamiento, en cuanto analiza las distintas alternativas posibles para razonar la solución elegida. Ésta ha de considerarse "contexto dominante" para el resto de la documentación del plan de suerte que a la hora de interpretarlo y superar sus contradicciones prevalece el sentido que derive de la memoria, cuya virtualidad interpretativa resulta ser, así, relevante» ${ }^{47}$.

En sexto lugar, Luciano Parejo Alfonso se ha referido sobre esta materia, sosteniendo que:

El plan general se expresa en una serie de documentos articulados entre sí, que -con carácter general- pueden agruparse de la siguiente forma:

\section{$[\ldots]$}

b) Desde el punto de vista de su contenido sustantivo y su alcance:

- Documentos convencionales y gráficos (planos) puramente informativos, que reflejan la situación relevante del territorio ${ }^{48}$.

46 Ricardo Santos Diez y Julio Castelao Rodríguez, Derecho Urbanístico, Manual para juristas y técnicos (Madrid: La ley-Wolters Kluwer, 20I2), 60I. Cita interna omitida. Énfasis añadido.

47 Ramón López Sales, "Régimen de las actuaciones urbanísticas sin título habilitante en la comunidad valenciana", (Tesis doctoral, Universitat Jaume I, 20I2), 300-30I. El autor cita como apoyo de su tesis a Javier Delgado Barrio, El control de la discrecionalidad, 53 y a Eva Desdentado Daroca, cuya obra, Discrecionalidad, ya hemos comentado más arriba.

Luciano Parejo Alfonso, "La ordenación urbanística (III): Instrumento de planeamiento", en Lecciones de derecho administrativo. Orden económico y sectores de referencia, ed. Por Luciano Pareja Alfonso, $2^{\mathrm{a}}$ ed. (Valencia: Tirant Lo Blanch, 20II), 395. Negritas en el original. 
Además, agrega que

Con carácter general, puede decirse que la jurisprudencia contenciosa administrativa da preferencia a los documentos directamente prescriptivos (planos de ordenación y normas urbanísticas) sobre los restantes y, a su vez dentro de éstos, a las normas sobre los planos. En todo caso, esa misma jurisprudencia (STS de 4 de enero de 2011) otorga un gran valor interpretativo a la memoria y concede importancia a la correcta formulación tanto de ella, como del estudio económico y financiero y de la programación de la ejecución, hasta el punto de que la diferencia o irrealidad de estos documentos (los cuales en ningún caso pueden reducirse a mera formalidad) pueden determinar la anulación del plano ${ }^{49}$.

A mayor abundamiento, el mismo autor se refiere expresamente a la Memoria Explicativa diciendo que «[e]n efecto, de un lado, la memoria es un documento capital para la justificación de las opciones o decisiones tomadas [...] en el plan general es decir, contribuye decisivamente a su motivación; y, de otro lado, la vocación de realización efectiva del modelo de ordenación adoptado que tiene el planeamiento urbanístico, hace que su viabilidad misma (y, por lo tanto su corrección jurídica) dependan también de la coherencia de las previsiones temporales y de los cálculos económicos y financieros correspondientes» ${ }^{50}$.

Del mismo modo, un séptimo autor, el profesor Ramón Parada, también resalta el rol esencial que tiene la Memoria Explicativa:

La Memoria es el documento explicativo y justificativo de los contenidos del Plan General. Es, con otras palabras, su motivación. Por ello ni debe ni puede entenderse como un puro ejercicio literario, sino como la legitimación última y completa de las determinaciones del Plan, pues-como dice la STS de 9 de julio 1991-no se trata «de un documento accidental que puede existir o no, sino una exigencia insoslayable de la Ley, ya que la profunda discrecionalidad del planeamiento, producto normativo emanado de la Administración y que pese a ello está habilitado para regular el contenido de la propiedad [...] explica la necesidad esencial de la Memoria como elemento fundamental para evitar la arbitrariedad. De su contenido ha de fluir la motivación de las determinaciones del planeamiento» ${ }^{51}$.

Ibid. Negritas en el original. Énfasis añadido.

Ibid. Énfasis añadido.

Ramón Parada, Derecho administrativo III. Bienes públicos. Derecho Urbanístico, $\mathrm{II}^{\mathrm{a}}$ ed. (Madrid: Marcial Pons, 2007), 36r. Cursivas en el original. 


\section{$\mathrm{X}$. La interpretación de la jurisprudencia de referencia}

Después de haber dejado claro que la doctrina española es clara y consistente en manifestar la preferencia de la Memoria Explicativa, la jurisprudencia de los tribunales españoles se ha inclinado por la misma postura. Así, en primer lugar, en su sentencia del día 4 de noviembre del año 1972, el Tribunal Supremo de España precisó que:

$\mathrm{C}_{4}^{\circ}:$ El planeamiento para que obedezca al criterio realista que quiere nuestra ley, ha de asentarse sobre unas reales posibilidades económicas, para lo que aquella exige -como documento esencial-un estudio de las etapas para realizar el plan y de los medios económicos financieros disponibles, en el parcial [art. 10. 2, e)], y memoria que debe integrar la documentación del "plan" y seguir su mismo régimen de elaboración. ${ }^{52}$

Dicho de otro modo, lo que estableció el Tribunal Supremo Español fue que la modificación del plan parcial de ordenación urbana del sector noreste de Gavá (Barcelona), fue anulada por falta de memoria y estudio económico-financiero ${ }^{53}$.

En segundo lugar, más clarificador aún, fue lo ocurrido en la localidad de Caudillo, en la ciudad de Valencia, España, en donde se originó un conflicto de interés por la omisión de una calle en el Plan de Ordenación del Municipio Valenciano.

En dicha localidad, el propietario de un solar colindante a una calle presuntamente desaparecida, solicitó al Ayuntamiento licencia para la construcción de un edificio sobre el solar que es propietario y sobre la calle omitida en el plano de alineaciones. Justificaba el solicitante en su presentación, que el plano no reconocía la calle colindante al solar, por tanto, era factible construir.

Pese a la lógica de su argumento, la licencia mencionada fue rechazada por la Corporación Municipal, preceptuando error de alineación y ausencia de deseo por parte de la Corporación para que la calle sobre la cual se pretendía construir desapareciera. La Corporación Municipal justificó su decisión en que la Memoria Descriptiva no contenía ninguna mención a la supresión de la calle.

Finalmente, quien resolvió dicha materia fue el Tribunal Supremo Español, que en su sentencia del día 28 de octubre de 1977 concluyó que «[d]ar preferencia a las prescripciones literales de la memoria sobre las gráficas de un plano con líneas superpuestas es una forma

\footnotetext{
52 Énfasis añadido.

53 Énfasis añadido.
} 
racional y lógica de interpretación $»^{54}$. En efecto, lo que hizo el Tribunal Supremo Español en este caso fue darle preferencia a la Memoria Descriptiva (Explicativa) por sobre las gráficas de un plano.

En tercer término, podemos traer a colación el famoso caso "del barrio de Orcasitas" en la cuidad de Madrid, España ${ }^{55}$. El año 1973 los vecinos del barrio de Orcasitas fueron expropiados por la Administración como trámite previo para realizar la nueva urbanización del barrio entero; como expropiados, habían recibido un justo precio, que se convino entre las partes y que no dio lugar, por ello, a ninguna reclamación, ya que habían recibido incluso viviendas en arrendamiento previo al desalojo de su barrio.

Pese a lo anterior, el profesor Eduardo García de Enterría fue el abogado de los vecinos y utilizó para su defensa el argumento de que la Memoria de los planes de urbanismos es un documento más del mismo y, por tanto, de obligado cumplimiento ${ }^{56}$. Es por ello que García de Enterría gestionó un proceso contencioso-administrativo para proteger los derechos de los vecinos afectados por esa expropiación.

En ese entonces, el Plan Parcial para la remodelación de la zona, aprobado en 1971, incluía en su memoria que una vez concluidas las obras, los vecinos-que habían sido realojados provisionalmente-ocuparían de nuevo las casas que se iban a construir. La Memoria decía expresamente que la urbanización se hacía para "realojar" a los vecinos. El desafío jurídico surgió porque el Ayuntamiento se negó a cumplir el compromiso. Sin embargo, la jurisprudencia de la época no apoyaba la pretensión de dichos vecinos. Más aún, sostenía ésta que la memoria del plan era una simple exposición de propósitos.

No obstante lo dicho por el Ayuntamiento, prevaleció el argumento sostenido por García de Enterría. En su considerando séptimo, la sentencia de la Audiencia Territorial de Madrid postuló cuatro ideas que guardan estrecha armonía con lo que venimos planteando:

1. La memoria es una parte del plan, y la obligatoriedad del plan implica la obligatoriedad del conjunto y de cada una de las partes.

Esto se desprende de:

Que bastaría poner de manifiesto la circunstancia de que referida memoria, por lo mismo que es parte de ese todo indiscriminado, constituido por el Plan, cuya obligatoriedad nadie discute, y en el que por mandato del apartado 2, a),

\footnotetext{
54 Énfasis añadido.

55 Agradezco al profesor Eduardo Cordero Quinzacara el haberme puesto al tanto de este caso.

56 Énfasis añadido.
} 
del artículo 10 de la Ley últimamente citada ha de insertarse, para afirmar, en acatamiento de la más estricta lógica, que si éste ha de ser vinculante en su totalidad, no podría tener eficacia esta obligatoriedad si no fueren idénticamente obligatorias y vinculantes todas y cada una de las partes esencialmente componentes de aquél, por lo mismo que dicho artículo 45 no limita, ni limitación alguna consiente, de este efecto a parcelas jurídicas, técnicas o materiales del planteamientos una vez aprobados, o a determinados o a específicos elementos constituyentes del mismo.

2. La memoria determina los objetivos del plan.

El considerando $7^{\circ}$ señala que:

ningún órgano gestor puede, material ni jurídicamente, realizar, sin la existencia y determinación de un rumbo previamente fijado como propósito, meta o finalidad perseguida, qué es y en qué ha de constituir lo que se va a llevar a cabo, que precisamente es el cometido específico de aquella y que, a todos los efectos, pone de relieve el substratum técnico y jurídicos de ese programa o proyecto, justifica su razón de ser o sentido, sienta las bases de ejecución, especifica el modo en que ésta ha de producirse y acredita la disponibilidad material y jurídica de los medios legales exigidos como imprescindibles para el feliz éxito de lo que urbanísticamente es proyectado.

3. Con base en la memoria es posible articular el control sobre el adecuado o inadecuado cumplimiento del plan.

En este punto y en el mismo considerando se abarca la trascendencia de la memoria, en cuanto a que:

la inevitable y consiguiente trascendencia que es lo que de ella (la memoria) resulta, lo que en Derecho se va a tener en cuenta para que, adverada la realidad de lo previsto o de lo que la Ley prevé, se determine la procedencia de ser aprobada la gestión futura, sin cuya aprobación ningún Plan puede ejecutarse válidamente ni, por supuesto, vincular ni siquiera a sus propios creadores, siendo secuela de lo dicho que no es posible degradar en supuesto alguno el alcance y trascendencia de dicha memoria, ya que de hacerse se podría llegar a que, incluso, resultare viable lo que en manera alguna consiente por Ley viabilidad, como ocurriría de aprovechar un Plan debidamente aprobado, y consiguientemente de su memoria, para en su ejecución prescindir de lo en esta trazado y variar la primitiva programación de la finalidad urbanística, habida cuenta de que esto podría implicar incluso efectiva incidencia en su supuesto de desviación de poder [...]. 
4. La memoria como causa del negocio jurídico urbanístico.

Este planteamiento se sigue en el final del considerando $7^{\circ}$ :

Lejos de poder ser considerada tan repetida memoria como vehículo portador de simples activaciones subjetivas reveladoras del personal propósito del gestor, constituye la auténtica causa, en sentido jurídico, determinante de un elemento esencial del negocio jurídico urbanístico, y por lo mismo, y en el propio orden de cosas, el expediente y medio de más significativa potencia de auxilio a la hermenéutica para solucionar eventos, como el de autos, en el que se pone en evidencia la disconformidad entre lo efectivo y materialmente realizado y lo jurídicamente realizable, por cierto, imponiendo al intérprete la necesidad de que cualquier situación conflictiva o dudosa haya de ser resuelta conforme a las previsiones que del contexto de la memoria sean deducibles, porque, como va dicho, fueron ellas precisamente las que engendraron la aprobación y consiguiente obligatoriedad del Plan, ya que el amparo y protección que lo ejecutable ha de merecer por parte del acto aprobatorio presupone de modo inexcusable la certeza que tiene la autoridad llamada a producirlo de que el fin propuesto no ha de sufrir alteración alguna en su ejecución material, y que, por supuesto, son legalmente aptas y viables todas y cada una de las consignaciones preceptivamente incluibles de la memoria, a la que, por lo mismo, la Ley impone el requisito de "justificativa", expresión sinónima de obligado acreditamiento de adecuación de medios a propuestos fines, como los genéricamente referidos a la ordenación de etapas para realizar el Plan y de los medios económicosfinancieros disponibles, que deberán dejarse afectados a la ejecución del mismo. ${ }^{57}$

En efecto, y en consideración a los argumentos del Tribunal Supremo de España, es que, sobre la base de lo sostenido por Eduardo García de Enterría, procede la Tesis expuesta por la Audiencia Territorial, que ratifica el reconocimiento de la pretensión de la Asociación de Vecinos de Orcasitas, estimando que «es una condición objetiva establecida en el Plan» y recapitulando sobre el significado y alcance de la memoria como «documento esencial del Plan» ${ }^{58}$.

Tal fue el revuelo de dicha sentencia y de los argumentos planteados por el destacado abogado García de Enterría, que hasta el día de hoy en la localidad de Mesitas de Orcasitas

57 Nemesio Rodríguez Moro, "Comentario monográfico: Plan especial que incluye parte de zona marítimo-terrestre redactado por un ayuntamiento", Revista de Estudios de la Administración Local I98 (I978), en Ángel Sánchez Blanco, "La memoria en el planteamiento urbano”, Revista de Administración Pública 86 (1978): 469.

58 Ibid. 
hay una plaza denominada "Plaza de la Memoria Vinculante"

Finalmente, de las tres sentencias citadas anteriormente podemos concluir que:

- Primero, la Memoria Explicativa es una parte del Plan Regulador, junto a los planos, y en conjunto forman un solo instrumento, que para los fines de su aprobación, modificación y aplicación constituyen un solo cuerpo legal.

- Segundo, dar preferencia a las prescripciones literales de la memoria (Explicativa) sobre las gráficas de un plano con líneas superpuestas es una forma racional y lógica de interpretación.

- Tercero, la memoria aprobada por la administración es vinculante y obligatoria.

- Cuarto, el preciso motivo de la memoria es la solución de eventos que se puedan producir al interpretar los instrumentos. Existiendo la necesidad de aclarar una situación conflictiva o dudosa, ésta ha de ser resuelta conforme a las previsiones que del contexto de la memoria sean deducibles, pues fueron ellas las que precisamente engendraron la aprobación y consiguiente obligatoriedad del Plan.

Es por todo lo anteriormente dicho que la Memoria Explicativa tiene carácter de preeminencia vinculante por sobre los demás instrumentos que componen el Plan Regulador, entendiendo a ellos como la ordenanza y los planos. Éstos, por cierto, se construyen sobre la base de lo ya indicado en la Memoria.

Es por esto que no podemos sino concluir que en la Memoria Explicativa se encuentra recogida la real intención del planificador en su máxima expresión, y por tanto la Memoria Explicativa es la herramienta que hace las veces de guía o instructivo respecto de los demás instrumentos, a su vez que sirve también como solucionador de conflictos a la hora de la interpretación de dichos instrumentos.

\section{Conclusiones}

1. El carácter legal de la Memoria Explicativa se encuentra reconocido en la Ley

La comunidad quiso denominarla "Plaza Eduardo García de Enterría", lo que no fue aceptado por éste. De allí que se diera el nombre que señalamos. Ver Eduardo García de Enterría, "Plaza de la memoria vinculante", $A B C$, 2 de mayo de 1991; Alex Niño, "El extraño nombre de la memoria vinculante", El País, 25 de marzo de 1997, http://elpais.com/diario/r997/03/25/ madrid/859292672_850215.html; Patxi Eguiluz y Carlos Copertone, "La memoria vinculante de Orcasitas", Architectural Digest España, 3I de enero de 20I7, http://www.revistaad.es/ arquitectura/articulos/la-memoria-vinculante-de-orcasitas/I8641. 
General de Urbanismo y Construcciones, en el Plan Regulador Intercomunal y en los Planes Reguladores Comunales.

2. En la Memoria Explicativa se encuentra retratada la intención del planificador, pues ella contiene todos los antecedentes que sirven de base o guía para la confección de los demás instrumentos que componen el PRMS.

3. Existe por tanto un orden de prelación entre los instrumentos de planificación, siendo la Memoria Explicativa el instrumento del cual derivan los demás, de modo que no puede sino ser ésta la que presida el proceso interpretativo.

4. La legislación, la jurisprudencia y la doctrina reconocen que debe existir una armonía entre todos los instrumentos de planificación, conformando todos ellos un solo cuerpo legal, tal como lo reconoce el Artículo Primero del PRMS.

5. Existe un orden cronológico en la confección de los instrumentos de planificación que componen el PRMS. Es decir, parte con la elaboración de la Memoria Explicativa, a partir de ésta el graficante dibuja el plano y finalmente se elabora la ordenanza.

6. La jurisprudencia y doctrina española han reconocido la relevancia de la Memoria Explicativa frente a los demás instrumentos que componen los Planes Reguladores.

7. Tratándose de las comunas de Las Condes, Lo Barnechea y Vitacura, el área de "preservación ecológica" comienza a partir de la cota 1.000 m.s.n.m. y no de la cota 900 m.s.n.m. 正 


\section{BIBLIOGRAFÍA}

- Alexy, Robert. La doble naturaleza del derecho. Madrid: Trotta, 2016.

- Delgado Barrio, Javier. El control de la discrecionalidad en el planeamiento urbanístico. Colección Cuadernos. Madrid: Civitas, 1993.

- Desdentado Daroca, Eva. Estudios sobre el acto administrativo. Madrid: Civitas, 1993.

- . Discrecionalidad Administrativa y Planeamiento Urbanístico. Construcción teórica y análisis jurisprudencial. Navarra: Aranzadi, 1999.

- Figueroa Velasco, Patricio y Juan Figueroa Valdés. Urbanismo y Construcción. Colección Tratados y Manuales. 2a ed. Santiago: Thomson Reuters, 2016.

- García De Enterría, Eduardo. De montañas y hombres. Colección Austral. Madrid: Espasa-Calpe, 1998.

- Hart, H. L. A. El concepto del derecho. Buenos Aires: Abeledo-Perrot, 1995

- López Sales, Ramón. "Régimen de las actuaciones urbanísticas sin título habilitante en la comunidad valenciana". Tesis doctoral. Universitat Jaume I, 2012.

- Parada, Ramón. Derecho administrativo III. Bienes públicos. Derecho Urbanístico. 11ª ed. Madrid: Marcial Pons, 2007.

- Parejo Alfonso, Luciano y Eduardo García De Enterría. Lecciones de derecho urbanístico. Madrid: Civitas, 1981.

- Parejo Alfonso, Luciano. "La ordenación urbanística (III): Instrumento de planeamiento". En Lecciones de derecho administrativo. Orden económico y sectores de referencia. Editado por Luciano Parejo Alfonso, $2^{\text {a }}$ ed., 193-509. Valencia: Tirant Lo Blanch, 2011. 
- Rajevic Mosler, Enrique Petar. "La propiedad privada y los derechos adquiridos ante la planificación urbana”. Revista Chilena de Derecho 25, nº 1 (1998): 65-112.

- Sánchez Blanco, Ángel. “La memoria en el planteamiento urbano”. Revista de Administración Pública 86 (1978): 469.

- Santos Diez, Ricardo y Julio Castelao Rodríguez. Derecho Urbanístico, Manual para juristas y técnicos. Madrid: La ley-Wolters Kluwer, 2012.

- Soto Bustos, Gabriela. "Régimen Jurídico de los Planes Reguladores”. Memoria de licenciatura. Universidad de Chile, 1996. 